\title{
Héroes luchadores: los valores esenciales de la tradición xia en la China antigua
}

Albert Dalia

Boston University (Estados Unidos)

Es traducción del artículo Fighting Heroes: The Core Values of the Xia Tradition in Early China, publicado en el Journal of A sian Martial Arts, volumen 20, número 3 (8-21), 2011

\begin{abstract}
Resumen
Los valores esenciales de la famosa literatura y cine chino denominada wuxia (ficción heróica) se desarrollaron como respuesta al caos y a la hostilidad del periodo de los Reinos Combatientes (475-221 a.C.). En inglés, probablemente la mejor fuente de información disponible en el mercado sobre este asunto es el libro del profesor universitario James J.Y. Liu, The Chinese Knight-Errant (1967), que desafortunadamente está descatalogado. El presente artículo se basa en ese libro y en el trabajo académico y literario del propio autor sobre el héroe del este asiático. Estos valores heroicos parecen anclarse en el individualismo, lo que contradeciría el sentido de cohesión de grupo del que hace alarde esa región.
\end{abstract}

Palabras clave: Artes marciales chinas, ética, ficción, literatura, cine.

Fighting Heroes: The Core Values of the Xia Tradition in Early China

Abstract: The core values of China's famed wuxia (heroic fiction) literature and cinema developed in response to the chaos and warfare of the Warring States Period (475-221 B.C.E.). In English, probably the best commercial source of information on this topic is Professor James J.Y. Liu's book, The Chinese Knight-Errant (1967), which unfortunately is out of print. This article is based on that book, along with the author's academic and literary work on the East Asian hero. These heroic values appear to be rooted in individualism, which would seem to contradict the region's vaunted sense of group cohesiveness.

Keyw ords: Chinese martial arts, ethics, fiction, literature, cinema.

Heróis lutadores: os valores essenciais da tradição xia na antiga China

Resumo: Os valores essenciais da famosa literatura e cinema chinês, denominados wuxia (fiç̧ão heróica) desenvolveram-se como resposta aos caos e à hostilidade do período dos Reinos Combatentes (475-221 a.C.). Em inglês, provavelmente, a melhor fonte de informação disponível no mercado sobre este assunto é o livro do professor 


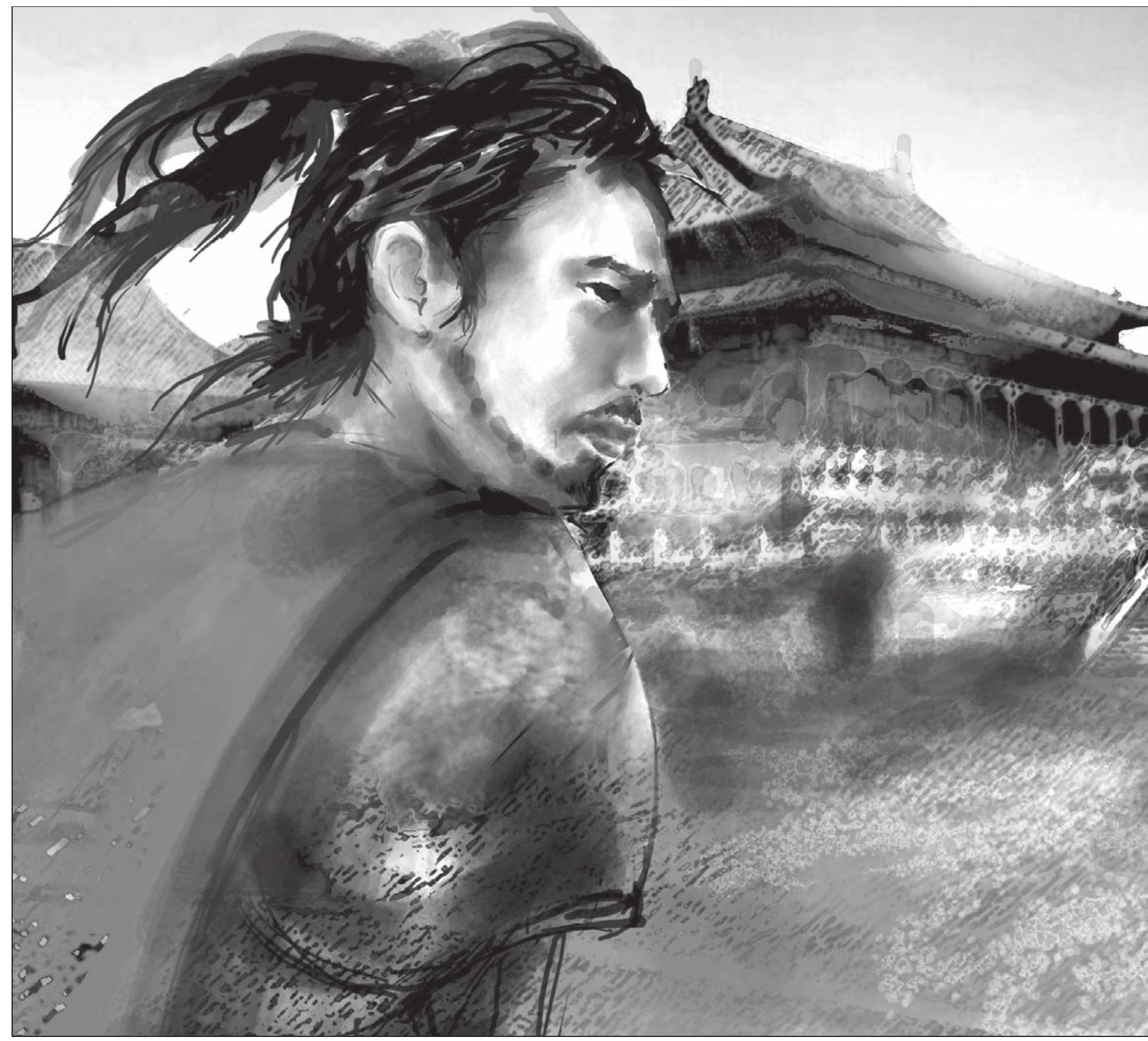

Todo el trabajo artístico de este artículo es obra del Jungshan Ink.

http://jung-shan. blogspot.com universitário James J.Y. Liu, The Chinese Knight-Errant (1967), que infelizmente não está catalogado. 0 presente artigo baseia-se neste livro e no trabalho académico e literário do próprio autor sobre o herói do Este asiático. Estes valores heróicos parecem situar-se no individualismo, o que contradiz o sentido de coesão do grupo que faz parte desta região.

Palavras-chave: Artes marciais chinesas, ética, ficção, literatura, cinema. 


\section{Héroes}

\section{luchadores:}

\section{los valores}

\section{esenciales de}

la tradición xia

\section{en la China}

\section{antigua}

Albert Dalia

Boston University (Estados Unidos)

\section{Introducción: Auge e ideales de los xia}

Wuxia xiaoshuo y pian (que traduzco como "ficción heroica" y "cine heroico", aunque tradicionalmente se ha traducido como ficción y cine "de artes marciales") han sido el principal sostén del entretenimiento popular chino. Su creciente popularidad en el mundo del entretenimiento globalizado es sobradamente conocida. Como académico sobre China y como novelista de wuxia, tengo interés en este género popular. En este artículo, me gustaría considerar brevemente los orígenes históricos de los personajes de ese género.

Mientras que los novelistas chinos actuales de wuxia parecen tratar sólo las dinastías Yuan (1280-1368), Ming (1368-1644) y Qing (1644-1911), tanto en mi trabajo académico como en el de ficción nunca me aventuré a pasar de los Tang (618-907). De hecho, prefiero la primera centuria de los Tang, su "época dorada". Y para la literatura wuxia, los Tang representan un período seminal, ya que es con los Tang cuando la ficción china da un gran salto con el auge de la historia breve. Sin embargo, para considerar el ascenso de los xia ("héroes marciales") en la historia China, tenemos que retrotraernos al período de los Reinos Combatientes (475-221 a.C.). 
"Sha" (matar): cortesía de Jungshan Ink.

http://jung-shan. blogspot.com

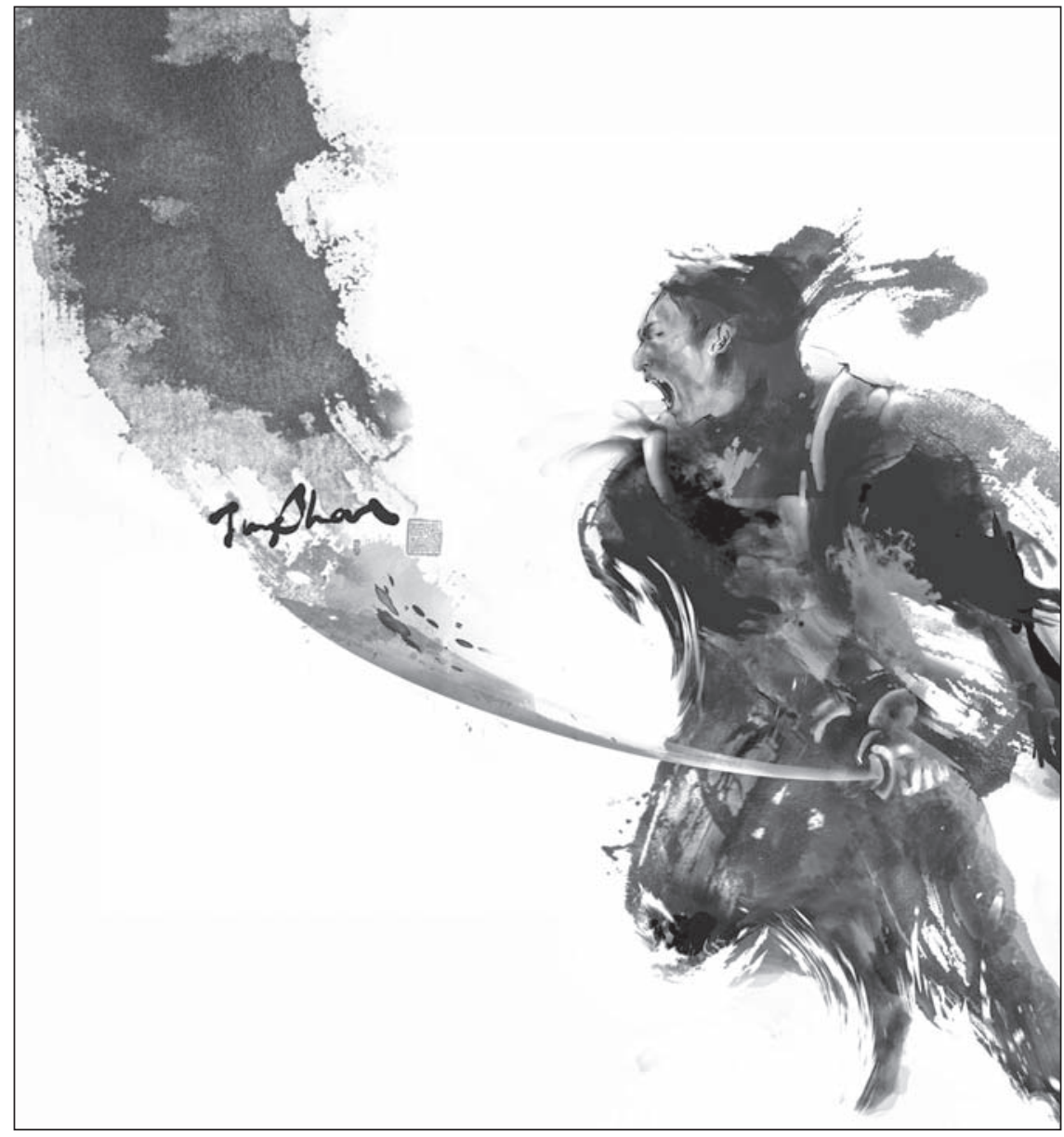

En relación a este artículo, el trabajo fundamental en inglés sobre la temática es el pequeño y maravilloso libro del profesor James J.Y. Liu (1926-1986), The Chinese Knight-Errant [El caballero errante chino] (1967). Aunque el libro está descatalogado, utilizaré numerosas citas del mismo ya que será más sencillo para los lectores que los artículos y libros escritos en chino.

El significado primero del carácter xia en la China antigua era "utilizar la fuerza para ayudar a la gente". Se hizo sinónimo de la palabra "caballería". El carácter xia vino a describir a este tipo de luchadores/héroes, puesto que su característica principal era el uso de la fuerza para ayudar a los demás. El carácter you, errar, vagar, se añadió a xia, produciéndose la combinación youxia, debido a que estos luchadores solían vagar por la tierra, ayudando a otros. En mi obra de ficción, he traducido youxia como "filos errantes", ya que escribo sobre héroes que utilizan armas de filo. Por esto, wuxia viene a traducirse literalmente como "el uso marcial de la fuerza para ayudar a los demás" o quizá como "caballerosidad marcial". En inglés lo usamos para referimos al género de "artes marciales" de la literatura y el cine.

En China, hasta donde sabemos, el carácter xia utilizado de este modo aparece en los escritos del eminente filósofo legalista Han Fei (韓非; ca. 280-233 a.C.) bajo el encabezado de "Las Cinco Alimañas". No parecería ser este un inicio auspicioso para la reputación de estos luchadores. Han Fei, siendo un defensor de la estricta norma conocida como "legalismo", consideraba peligrosos para el Estado tanto a los confucianistas como a los xia. Escribió, "[L]os confucianistas traen confusión a la ley con su aprendizaje; los caballeros violan las prohibiciones con sus hazañas militares". Más aun, que "aquellos hombres que llevan espadas, atacan y asesinan son personas violentas y extremas y aunque la sociedad los considere como rectos y valerosos, los bandidos y los hombres que esconden a traidores deberían ser condenados a muerte, pese a que la sociedad los considere hombres de honor" (Lai, 1999: 89).

Sin embargo, la mayor influencia en la ficción wuxia posterior fueron los Registros del Gran Historiador (Shi Ji), del gran historiador Sima Qian (145-86 a.C.). Fue el mayor historiador chino y quizá un hombre que compartía cierta ética wuxia por su determinación para continuar con la visión de su padre 
sobre la gran historia de China. Sima Qian defendió honorablemente la reputación del general derrotado ante las injustas acusaciones del emperador, y por ello el emperador lo condenó a muerte.

La ley de aquel tiempo dictaba que las sentencias a muerte podían ser conmutadas mediante un pago o mediante una mutilación. Sima Qian no tenía dinero y sufrió la humillación y el dolor de la castración en vez de la muerte. Hizo tal cosa para poder continuar con el sueño de su padre de que su familia compusiera una historia de China. Sima Qian vivió para finalizar los Registros del Gran Historiador. Sentó los estándares no solo para las subsiguientes historias escritas en China, sino que tuvo influencia en el ascenso y la composición de las obras de ficción durante la dinastía Tang. Su escritura no solo aportó la forma que tomaría la obra de ficción Tang (el uso del desarrollo de los personajes y la línea narrativa), sino que además aportó un campo fértil para esas primeras historias breves - las aventuras de los xia se encuentran por primera vez en la literatura china en la literatura Tang chuanqui ("narraciones de cosas admirables" 0, simplemente, "cuentos maravillosos")-.

En sus Registros, Sima Qian inició la forma biográfica como un género histórico. "Entre estas biografías, el capítulo titulado "Biografías de los caballeros andantes" ("Youxia liezhuan') probablemente tuvo la mayor influencia en la posterior ficción de caballerías andantes" (Lai, 1999:88). ¿Cuál era la opinión de Sima Qian sobre los xia?

A diferencia del filósofo legalista Han Feizi, que nos ofrece la primera mención del xia en la literatura, Sima Qian mantiene una postura diferente frente a sus acciones cuando escribe:

Hablando ahora de los caballeros andantes, si bien sus acciones no estaban de acuerdo con las normas de propiedad, siempre dijeron lo que creían, siempre conseguían lo que se habían propuesto, y siempre cumplieron sus promesas. Se apresuraron para ayudar a hombres en problemas sin pensar por un momento en su propia seguridad. Y cuando salvaron a alguien del desastre aun a riesgo de su propia vida, nunca alardearon de su habilidad y se hubieran avergonzado de pavonearse de su benevolencia. De hecho, hay mucho que decir en su favor. Más aún, el desamparo es algo con lo que todo el mundo puede toparse en un momento dado.

- Liu, 1967:14
"Puño de sangre": cortesía de Jungshan Ink.

http://jung-shan. blogspot.com

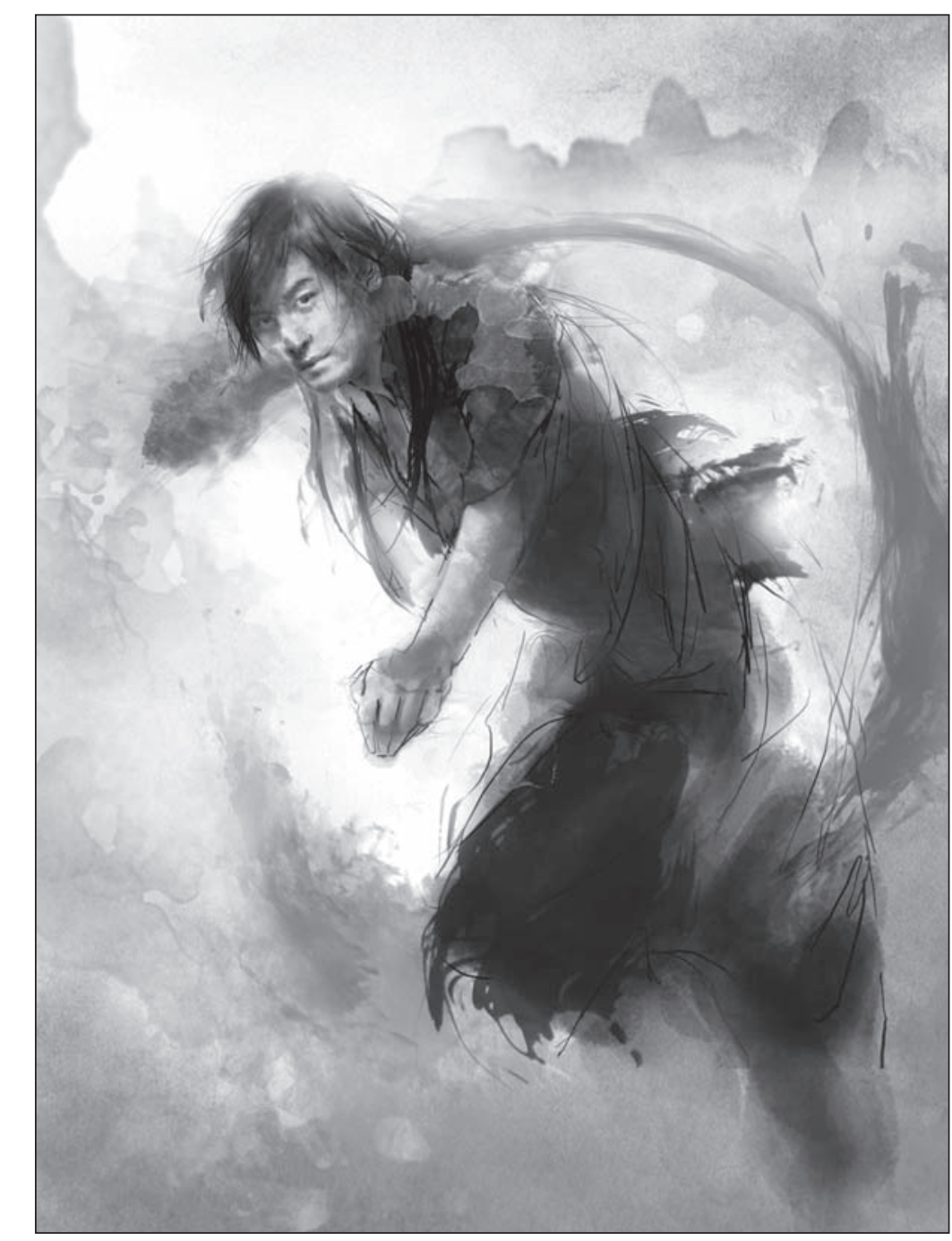


¡Y esto lo escribe el historiador que sufrió la castración debido a su integridad! Podemos ver aquí una definición temprana del "uso de la fuerza para ayudar a las personas" de los xia.

Sobre los orígenes sociales de los xia, el profesor Liu toma en consideración tres opiniones expertas:

- Eran campesinos y artesanos desempleados, plebeyos que se hicieron guerreros profesionales.

2 Eran hombres sin propiedad, pero no exclusivamente de origen social humilde, e incluso algunos podían haber sido nobles que perdieron su estatus.

3 No eran un grupo social particular, sino simplemente hombres con un temperamento caballeresco.

Liu se inclina hacia la última opción y concluye diciendo que, "sugiero que es mejor considerar a los caballeros andantes no como una clase social o grupo profesional, sino simplemente como hombres de un marcado temperamento individualista, que se comportaron de cierto modo basándose en ciertos ideales" (Liu, 1967: 4).

El profesor Liu escribe (1967: 4-6) que al leer la literatura de este antiguo período, ha encontrado ocho ideales básicos que se relacionan con el xia: 1) altruismo, 2) justicia, 3) libertad individual, 4) lealtad personal, 5) coraje, 6) honestidad y fe mutua, 7) honor y fama, y 8) generosidad y desprecio por la riqueza. Seguiré la presentación del profesor Liu, ya que su libro es difícil de encontrar, y añadiré mis propios comentarios cuando sea posible.

\section{Los ocho valores básicos del Xia}

\section{Altruismo}

El "altruismo" es la traducción que el profesor Liu hace del carácter chino yi (義). Este era también un concepto principal en las enseñanzas de Confucio (551-479 a.C.), que vivió durante el período de los Reinos Combatientes sobre el cual estamos hablando. Él era uno de esos académicos errantes que trataban de impresionar a los Reinos Combatientes con sus soluciones, compartiendo época con "nuestros" caballeros errantes -cuyas "soluciones" tendían a ser más directas-. El yi confuciano de la primera etapa se traduce frecuentemente como "rectitud".

Liu destaca que el moderno filósofo chino Feng Yulan consideraba que yi, tal y como lo entendían los xia, "significaba nada más que aquello que exigen los estándares comunes de moralidad". Y cita este ejemplo, "Ser amable y no esperar recompensa es moral: ser amable y rechazar cualquier recompensa es supermoral". Así pues, yi en este contexto se entiende como una especie de "supermoralidad" (p. 4).

Sin embargo, hay otra forma de entender yi. Una interpretación interesante me la proporcionó un antiguo amigo de la universidad de Hawai, Roger T. Ames, en su traducción con Henry Rosemont, Jr. de Las Analectas, la antigua colección de las enseñanzas de Confucio. Estos dos académicos se fijan en las variantes del 
carácter registrado en la dinastía Shang (ca. 1766-ca. 1050 a.C.) y concluyen que "moralidad" no es el sentido correcto del carácter (Ames \& Rosemont, 1999).

Ames y Rosemont argumentan que "apropiado" o "adecuado" son equivalentes ingleses más cercanos a yi en ese contexto histórico/intelectual. Como ellos mismos explican:

$\mathrm{Yi}$, entonces, es el sentido que uno mismo tiene de lo apropiado, que permite actuar de modo adecuado, dada una situación específica. Es por el hecho de que yi es el sentido de lo apropiado que hace que las relaciones sean verdaderamente significativas en una comunidad con mutua confianza, que Confucio dice: "hacer el bien en la propia palabra (xin) acerca a uno hacia lo apropiado".

- Ames \& Rosemont, 1999:54-55

Creo que esa interpretación, aunque se refiere al uso temprano del término por parte del confucianismo, podría encontrar cierta resonancia con la ética xia. Sima Qian, como se indicó anteriormente, observó que aunque el xia tendía a alardear sobre la regla de la propiedad, eran fieles a su palabra ¿Podemos entonces decir que sus acciones, aunque quizá contrarias a las normas de la época sobre la propiedad, eran "apropiadas" para la situación que se les presentaba, tal y como ellos la entendían? En otras palabras, su sentido de yi era relativo, situacional.

\section{Justicia}

Liu considera que el sentido de los xia de "lo apropiado" (utilizando la interpretación de Ames y Rosemont) surge de su sentido de justicia, el cual (y esto es significativo en la sociedad confuciana) "sitúan por encima de la lealtad familiar". Ofrece ejemplos emotivos de este periodo de la historia del caballero errante Kuo Hsieh (ca. 127 a.C.) (pp. 4-5). Resumiré la traducción de Liu, procedente del registro histórico de Sima Qian.

Kuo Hsieh era de la provincia de Honan. Su padre era un caballero errante que fue ejecutado por el Emperador Wen (que reinó del 179-157 a.C.). Cuando era joven, Kuo era rencoroso y mató a muchos que lo ofendieron. "Vengó los entuertos privados de sus amistades a riesgo de su propia vida, escondió a aquellos huidos de la ley, robó a gente e incluso robó tumbas, y acuñó moneda de forma ilegal. Cometió esos crímenes infinidad de veces pero o bien escapó o fue perdonado por amnistía". Cuando se hizo mayor se reformó, pero mantuvo su carácter vengativo. Sin embargo, cuando salvaba la vida de alguien, nunca se vanagloriaba de ello. Muchas veces actuaba como árbitro objetivo en diversos casos de disputa. Sin embargo, las autoridades gubernamentales, cansadas de los disturbios provocados por Kuo o sus seguidores, presentó cargos contra él, argumentando que, "Kuo Hsieh es un plebeyo que se dedica a la caballería andante y concentra un gran poder. Mataría por una pequeña ofensa... merece la pena de alta traición". Kuo y toda su familia fueron ejecutados (Liu, 1967: 37-40). Existe un incidente en su vida que merece la pena recuperar de Liu con un mayor detalle: 


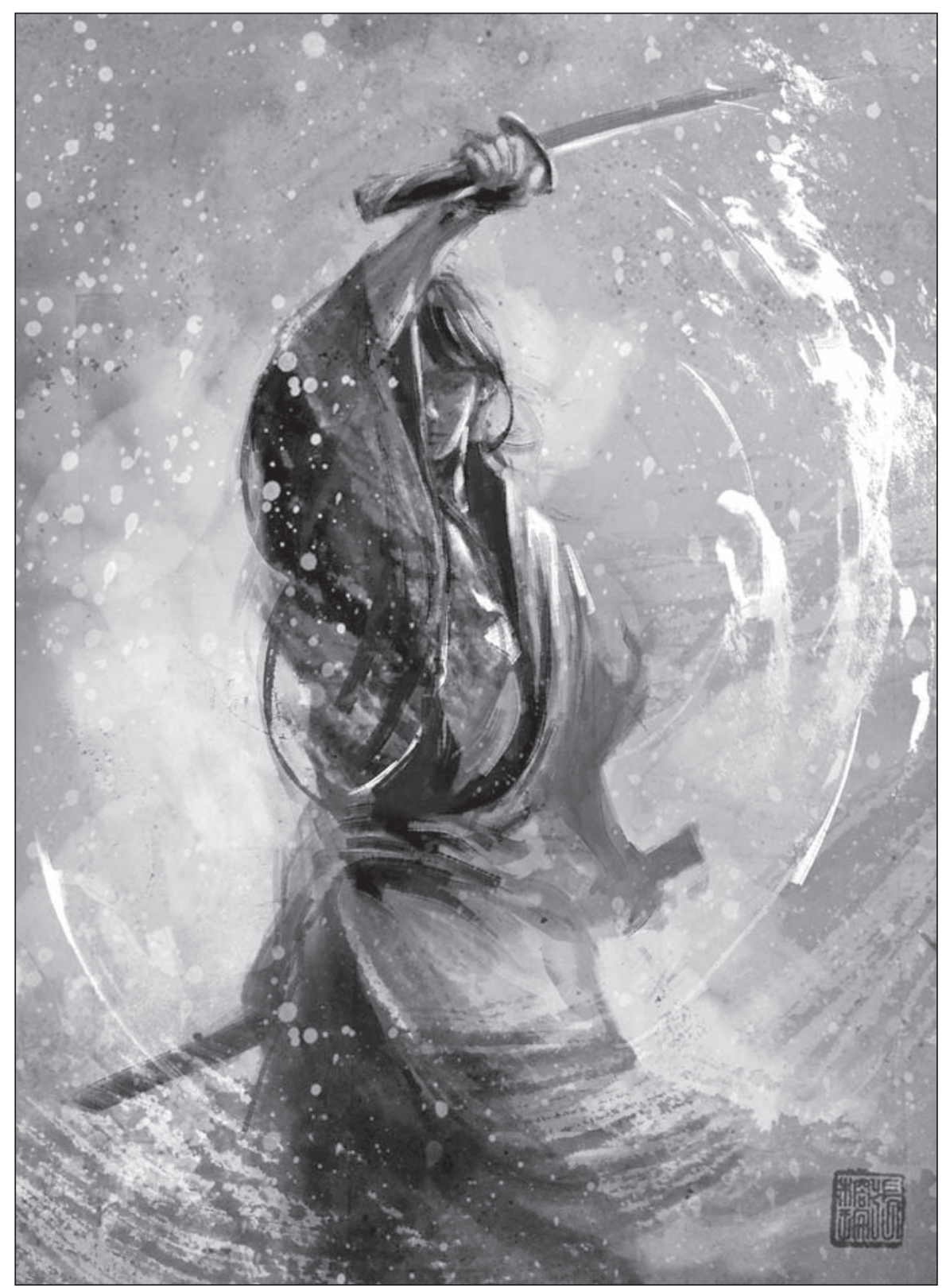

"Dororo". Cortesía de Jungshan Ink.

http://jung-shan. blogspot.com.
Una vez, el hijo de la hermana de Kuo Hsieh, confiando en la influencia de Kuo, obligó a otro hombre a beber más allá de sus capacidades. Este último se enfadó, mató al joven y huyó. La hermana de Kuo, enfadada porque el asesino había escapado dijo, "Mi hermano es conocido por su altruismo [0 comportamiento "apropiado"], ipero ahora no puede siquiera encontrar al asesino de mi hijo!". Así que dejó el cuerpo de su hijo en el camino, se negó a enterrarlo y de ese modo avergonzaba a Kuo Hsieh. Finalmente Kuo descubrió quién era el asesino y este, en su desesperación, vino a verle de forma voluntaria y le contó toda la verdad. Kuo dijo, "Fue culpa de mi sobrino, hiciste bien en matarlo". Así que dejo irse al asesino y enterró a su sobrino tranquilamente. Todos aquellos que oyeron esto lo admiraron al poner la justicia por encima de la lealtad familiar, y más y más hombres vinieron a seguirle.

- Liu, 1967:38

El comportamiento de Kuo no le nominaría al premio al ciudadano modélico. Como mucho podría considerársele como un forajido o un gánster menor con cierta conciencia. Resulta interesante, sin embargo, que Liu cite el trato que tuvo Kuo hacia el asesino de su sobrino como ejemplo del "sentido de la justicia" xia. Y es desde este "sentido de la justicia" que surge su "altruismo".

Lo que me interesa como novelista es que el comportamiento de Kuo en su consideración de la "justicia" hacia su sobrino parece encajar bien con la definición de "apropiado" que cité para el término yi ("altruismo" en la traducción de Liu). Kuo trata al asesino de su sobrino en lo que él considera que es la forma "apropiada", o citando a Sima Qian de nuevo, "no de acuerdo con la regla de la propiedad", es decir, no en concordancia con las normas sociales. 


\section{Libertad individual}

Parece que la clave para el comportamiento xia es el ideal que parece más antitético a la norma socio/cultural china, tal y como es definida en el Confucianismo -libertad individual o individualismo-. Mientras que este es el tercer ideal en la lista de Liu, yo lo pondría en la cima. Como explica Liu:

No sólo manifestaron los caballeros su naturaleza rebelde, desafiando de modo abierto a la ley tratando de hacer justicia, sino que además mostraron su disconformidad en la vida cotidiana viviendo en lo que se llamaría hoy día un modo bohemio y prestando poca atención a las convenciones sociales.

- Liu, 1967: 5

¿Podría ser quizá este hecho lo que haga que esas historias de caballeros errantes sean tan atractivas para los aficionados occidentales? Posiblemente, ipero no podemos olvidar que este género es también el más popular en Asia oriental! Estos hombres y mujeres (!) eran muy individualistas. Li An (Ang Lee) lo transmite bien en el personaje de Zhan Ziyis de la película Tigre y dragón. Pero esto no es nada nuevo. Hemos podido observar las mismas características en infinidad de películas de artes marciales. Y en la tradición literaria, los espadachines se remontan al menos a la dinastía Tang.

Además, las variadas formas de las artes marciales son la propia expresión del individualismo, tal y como lo son muchas formas de arte en el Este Asiático. Aquellos de ustedes que practican artes marciales saben por propia experiencia que los profesores son muy individualistas y que aunque todos entrenamos con un sentido de comunidad en nuestros movimientos e interacciones con nuestros estudiantes y profesores, estas habilidades generan cierto sentimiento de autoconfianza. $Y$ aquellos que practican con pinceles de pintura o caligrafía comparten las mismas experiencias. La disciplina nos hace suficientemente fuertes como individuos para controlar (esperemos) nuestros egos, si bien a la vez nos hace fuertes para saber cómo expresarnos en caso de que fuese necesario -yo diría, para atrevernos ¡cuando "sea apropiado"! Y esto puede darse tanto en situaciones sociales como en un papel de arroz-.

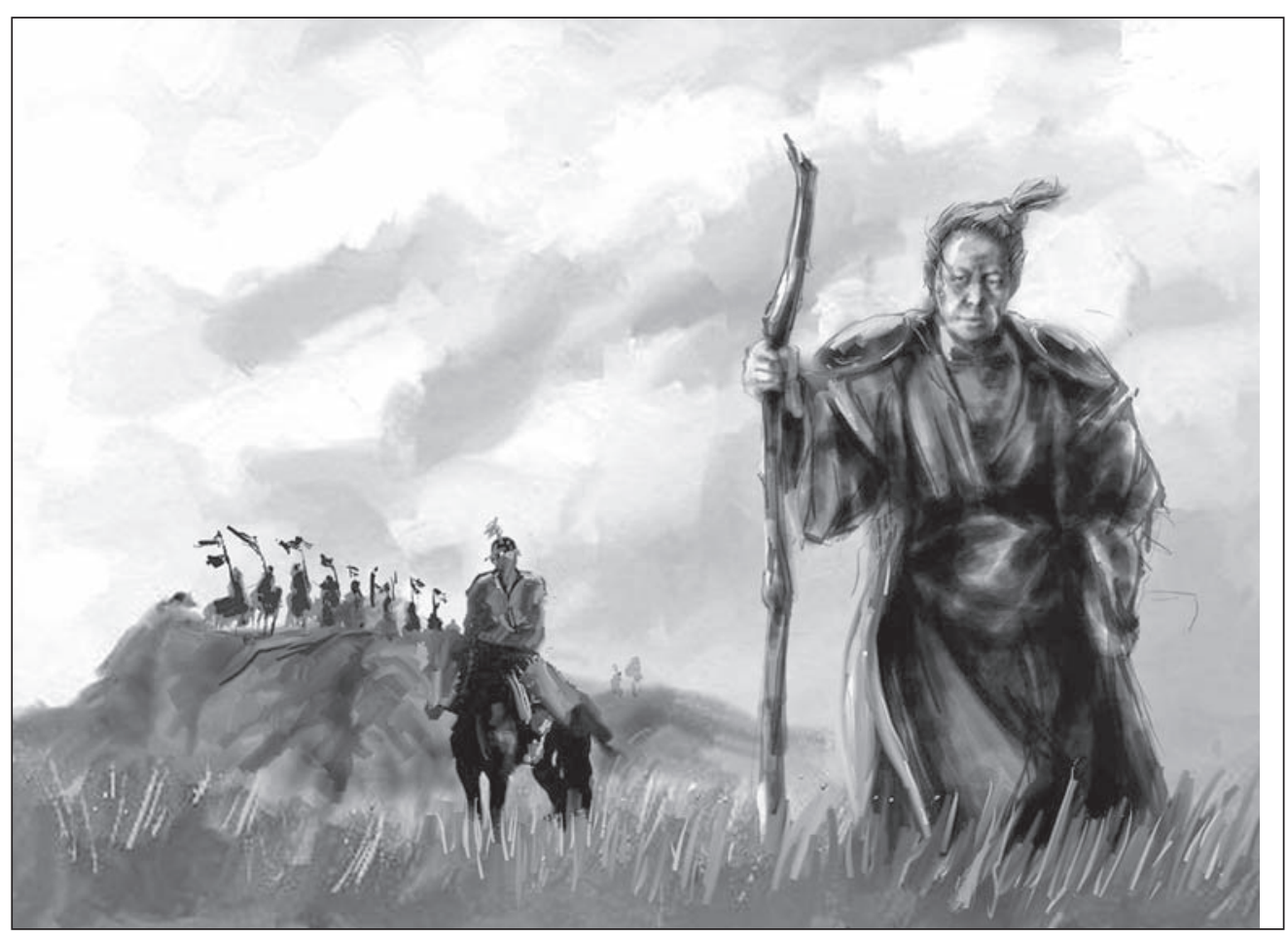


Por tanto, en cierto nivel, podemos entender los valores del xia como expresiones de individualismo. Esto no quiere decir que los seguidores de Confucio y de las otras escuelas de la época no fueran individuos, sino que sus expresiones de individualismo eran distintas. Tradicionalmente un seguidor de Confucio preferiría mantener un pincel de caligrafía en vez de la espada para enmendar agravios. Pero como los xia, ellos no dudarían en afrontar un agravio. El primer emperador de China, Qinshihuangdi (259-210 a.C.) enterró vivos a eruditos confucionistas que se oponían a él, y ejecutó a los xia que trataron de asesinarlo (las películas El emperador y el asesino y, en menor medida Hero, están basadas en incidentes registrados por Sima Qian). Ambos grupos estaban amenazando de tal modo su mandato opresor que creyó necesario eliminarlos.

\section{Lealtad personal}

Liu considera que el sentido xia de la lealtad personal trasciende su lealtad al que gobierna/el estado o a los padres/familia. Este aspecto particular de los valores xia entraba en abierto conflicto con la tradición confuciana, que enseñaba que los cinco tipos de relación (regente-súbdito, padre-hijo, marido-mujer, hermano mayor-hermano menor, entre amigos) eran las bases de la sociedad civilizada.

La cultura xia ponía énfasis en zhi-ji, un sentido de "lealtad" que cortocircuita las cinco relaciones. Hamm (2004: 13) daba el sentido a ese valor cuando citaba a Yu Rang, anotado en el registro del asesino de Sima Qian: "Un hombre morirá por alguien que le entienda, así como una mujer se hará más bella para alguien que se deleita en ella".

Una variación de este tipo de lealtad es la famosa historia de Bo Ya, un músico de este período antiguo que destrozó su laúd cuando Zhong Ziqi murió. De acuerdo con Bo, Zhong era la única persona que podía entender su música, el único que podía intuir el corazón del músico. Ese sentido de lealtad es conocido como zhi-yin, que en un diccionario moderno de chino se traduciría como "amigo íntimo".

Ese sentido especial de amistad 0 apreciación era la base de las relaciones sociales de los xia. Tales relaciones, desde una perspectiva confuciana y del estado, podían amenazar los pilares de la sociedad. Por tanto, encontramos a xia como Kuo Hsieh, que ayudaban a criminales a escapar y a vengar ofensas hechas a sus amigos o iban contra su familia dejando que el asesino de su sobrino se marchase sin castigo. La amistad xia podría minar la forma ortodoxa de orden social chino, de ahí la definitiva ejecución de Kuo Hsieh por el Estado.

\section{Coraje}

Esto debería ser obvio y no necesita mayor explicación, excepto remarcar lo que Liu dice sobre la actitud del caballero xia hacia la muerte que "casi sugiere que no tenían en gran consideración la vida" (p. 5). Creo que esto es un poco extremista. Mi lectura de sus biografías sugiere que tuvieron un deleite desorbitado por estar vivos, si bien no estaban apegados a ello. 


\section{Honestidad y fe mutua}

Citando nuevamente a Sima Qian, "Siempre decían las cosas en serio, siempre llevaban a cabo lo que se proponían, y siempre alcanzaron sus promesas". Liu dice que irían tan lejos como para suicidarse para mostrar su sinceridad (pp. 5-6).

\section{Honor y fama}

Liu dice que ese valor está conectado al anterior. Cita al gran historiador Sima Qian: "Disciplinaron sus acciones y cuidaron sus honores para que su fama se expandiese por todo el imperio". Liu considera que si bien no estaban motivados solo por "altruismo", su único motivo egoísta era su deseo de fama" (p. 6).

\section{Generosidad y desprecio por la riqueza.}

Liu argumenta que los xia no tenían problemas en aceptar o rechazar dinero de amigos, ya que no tenían un sentido fuerte de la propiedad. Podían vivir frugalmente y compartir con sus amigos, o vivir modestamente y compartir con los pobres (p. 6).

\section{Conclusiones}

Sobre la base del estudio de Liu, está claro que escritores chinos posteriores, primero en la dinastía Tang, desarrollaron el género literario wuxia a partir de esos primeros héroes chinos, y las historias de sus hazañas se transmitieron y expandieron. Estos ideales antiguos influenciaron fuertemente a lo que estaba por venir, no solo en la tradición literaria china sino también en el cine wuxia.

Más aun, esos ideales no se limitaron a China. En el programa de escritura de la Universidad de Boston imparto clases dedicadas al héroe/heroína del este asiático -la clase enfatiza una mezcla de películas chinas y japonesas-. Mis estudiantes y yo hemos descubierto que esos ideales se han mantenido con fuerza durante los dos últimos milenios, cruzando desde la literatura tradicional china hacia los medios de comunicación y el cine, y posteriormente siendo globalizadas por las tendencias contemporáneas del entretenimiento. La influencia regional de la tradición china wuxia también repercutió en las tradiciones guerreras de culturas adyacentes al área de influjo de China. Parece que el altruismo que emerge de ese sentido de justicia está en el corazón de esos valores. Pero ese sentido de altruismo deriva de una noción fuerte de individualismo, y es este sentido de individualismo en la cultura el que representa la base del título de mi curso: Paradoja del héroe/heroína en el cine y la ficción del este asiático. ¿Cómo hace una región cultural que está definida por su énfasis en la cohesión de grupo para dar a luz y rendir homenaje a héroes que exhibían un sentido tan fuerte de individualismo? Si los héroes de una cultura representan los estándares de comportamiento más elevados, entonces, ¿qué nos dice esta tradición heroica de la cultura del este asiático? Es más, fuera de la región del este asiático, ¿qué explica la fascinación por esa antigua tradición heroica? 


\section{REFEREN CIAS}

Ames, R. \& Rosemont Jr., H. (1999). The analects of Confucius: A philosophical tradition. New York: Ballantine Books.

Hamm, J. (2004). Paper Swordsmen: Jin Yong and the Modern Chinese Martial Arts Novel. Honolulu: University of Hawaii Press.

Lai, S. (1999). From cross-dressing daughter to lady knight-errant: The origin and evolution of Chinese women warriors. En Sherry J. Mou (Ed.), Presence and Presentation: Women in the Chinese Literati Tradition. (pp. 77-107). New York: St. Martin's Press.

Liu, J. Y. (1967). The Chinese knight-errant. London: Routledge and Kegan Paul.

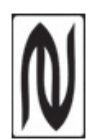

